\title{
OFRECIMIENTO Y CORTESÍA EN FRANCÉS ${ }^{1}$
}

\author{
LEYRE RUIZ DE ZAROBE \\ (Universidad del País Vasco)
}

\begin{abstract}
The aim of this paper is to examine the speech act «offer» in French in the light of somc assumptions proposed by Brown and Levinson in their theory of linguistic politeness. In order to do so, we analyse the effects of several linguistic formulations over the four faces that come into play in the interaction (the speaker's positive and negative face, and the addressee's positive and negative face). Although the speech act «ofter» is defined both as a threatening act of the speaker and addressee's face and a llattering act of the speaker and addressee's face, the linguistic formulations bound to carry out the act do not bring these relations into play similarly or with the same intensity. We conclude that offering in French implies threatening the other's territory and that the linguistic strategies routinized tend to minimize that threatening effect.
\end{abstract}

\section{Introducción}

De acucrdo con la teoría de la cortesía de Brown y Levinson, asumimos que los actos de habla ejercen una acción sobre una de las llamadas «faces» (o imágenes sociales) de los interlocutores. Para estos autores, toda persona posee una doble imagen : la imagen positiva, y la imagen negativa. La imagen positiva se refiere a la necesidad que todo individuo tiene de ser aceptado, de ser tratado como miembro de un grupo, de saber que sus propios deseos son compartidos por los demás. La imagen negativa se refiere a la necesidad que también posee todo individuo de ser independiente, de tener libertad de acción, y de no sufrir imposiciones por parte de otros.

En la comunicación, estas dos tendencias, contradictorias, generan conflictos, y aquí sc situán los procedimientos de cortesía, que permiten conciliar el deseo de los

\footnotetext{
'Estc trabajo sc enmarca en el PI 96/21 (Gobierno Vasco)
} 
interlocutores de mantener sus imágenes con el hecho de que muchos actos amenazan una u otra de las imágenes. En la comunicación, en general, se tiende a preservar las imágenes, la propia y la ajena. Se busca atenuar los actos que pueden resultar amenazantes para el otro (Face-Threatening Act-FTA- en la terminología brown-levinsoniana), por medio de cortesía negativa, dirigida a la imagen negativa del interlocutor, o por medio de cortesía positiva, dirigida a la imagen positiva del interlocutor.

En una interacción, se produce pues una implicación de esas dos imágenes, positiva y negativa, tanto del locutor, como del interlocutor. Nuestra hipótesis es que un mismo acto de habla puede impactar de manera diferente sobre las imágenes de los protagonistas de la interacción. Un mismo acto de habla se realiza generalmente por medio de estrategias lingüísticas diversas, y no todas implican de la misma manera a esas imágenes de los interlocutores, ni tienen los mismos efectos sobre ellas. Por ejemplo, en el caso del ofrecimiento, que se entiende beneficioso para la imagen positiva ajena, no es lo mismo decir:

Allez, je vous accompagne, que

Est-ce que je peux vous accompagner?

La primera es más firme, muestra mayor implicación del locutor y le induce más al interlocutor a la aceptación, que la segunda.

El objetivo de este trabajo será estudiar las implicaciones de las imágenes de los interlocutores en las distintas realizaciones lingüísticas del ofrecimiento, y con ello, los procedimientos de cortesía involucrados en esas distintas estrategias.

Este trabajo se enmarca pues en la línea de estudios de pragmática sobre cortesía, y adoptará la terminología brown-levinsoniana de «imagen positiva/negativa» $\mathrm{y}$ «cortesía positiva/negativa».

\section{El acto de habla «ofrecimiento» y la implicación de las imágenes de los interlocutores}

De los diversos actos de habla, el ofrecimiento representa uno de los poco estudiados, al contrario que la petición, por ejemplo, probablemente el acto de habla que ha suscitado mayor investigación. Es curioso constatar lo siguiente: si aceptamos que el ofrecimiento es la vertiente opuesta a la petición, los estudiosos de los actos de habla han considerado de mayor interés uno de dichos actos y no el otro, probablemente por la multiplicidad y tipo de cualificación de las estrategias comunicativas que se utilizan para su realización, y por tanto por resultar su estudio muy fructífero para una teoría de los actos de habla. Sin embargo, veremos que el ofrecimiento también nos sitúa frente a plurales mecanismos, no de menor interés 
que los de la petición, y que nos llevan a reflexionar sobre la naturaleza de este acto social.

¿Cómo delinimos el acto de habla «ofrecimiento»? Para definirlo y delimitar claramente su territorio frente a actos de habla similares, como la proposición o la invitación - con quienes se confunde a menudo-, tomamos como criterios de definición los siguientes parámetros (Tsui, 1994):

-cl agente de la acción futura (locutor y/o interlocutor)

-el beneficiario de la acción (locutor y/o interlocutor)

El ofrccimiento solicita la acción futura del locutor (no del interlocutor, en esto se distingue de la invitación, que solicita la acción del interlocutor, o de la proposición, que solicita la acción a la vez del locutor y del interlocutor) y se realiza para beneficio del interlocutor (no del locutor, en esto se distingue de la proposición, que beneficia a la vez al locutor y al interlocutor):

$$
\text { acción del locutor } \rightarrow \text { beneficio del interlocutor }
$$

Desde la perspectiva de la implicación de las imágenes de los hablantes, el acto de habla «ofrecimiento», globalmente contemplado, puede considerarse una acción con una doble cara:

1) Representa un acto amenazante (FTA) para la imagen ajena y de uno mismo, al menos en alguna de sus vertientes.

Si cada individuo de la interlocución posee dos imágenes, la positiva y la negativa, cl ofrecimiento representa potencialmente:

-Un acto amenazante para la imagen negativa del otro. Ofrecer algo a alguien es entrar en la privacidad del otro, en el territorio del otro, que se ve obligado a aceptar o rechazar mi ofrecimiento. Se trata de un acto no solicitado por el interlocutor, que parte de la iniciativa del locutor, y que por tanto, puede resultar intrusivo para el interlocutor. Por otra parte, ofrecer supone en muchos casos crearle una deuda al receptor de mi ofrecimiento, que puede sentirse en el deber de tener que devolvérmelo ${ }^{2}$, y que corre el riesgo de perder su imagen si no lo hace.

\footnotetext{
${ }^{2}$ Esto es particularmente frecuente en las culturas «debt-sensitive». No es el caso de nuestras culturas occidentales, donde el ofrecimiento no es un acto muy amenazante para el otro en el sentido indicado arriba, pero es el caso de la sociedad japonesa donde ofrecer algo, por pequeño que sea, puede ocasionar una tremenda deuda.

Con todo, este fragmento de Lacroix (1990: 341) ¿no ilustra el funcionamiento de FTA del ofrecimiento en nuestra sociedad?:

«Le don provoque un déséquilibre dans la relation à autrui. Quand nous donnons, nous faisons d'autrui notre débiteur. Nous compliquons donc son univers mental, en y introduisant un élćment perturbateur. Nous compromettons le sentiment serein qu'il avait d'être quitte envers nous. Celui qui reçoit ćprouve une confusion, une impatience de se libérer par un don réciprocjuc. Nous sommes comptables de cet effet induit par notre dons.
} 
Aunque lo siguiente se refiere a la invitación, puede ser también válido para el ofrecimicnto:

«En el caso de las invitaciones, el patrón interaccional es bastante complejo debido al hecho paradójico de que el interlocutor que acepta una invitación no sólo se ve bencficiado, sino también amenazado por la misma. La amenaza está en que. al aceptar la invitación, el invitado corre el riesgo de dar la impresión de pensar sólamente en su propio provecho. Por esta razón se da por hecho que contrae una deuda con quien invita, que le obliga, en principio, a restablecer el equilibrio del balance coste-beneficio correspondiendo a la invitación cuando se dé la oportunidad. Al mismo tiempo, al que acepta la invitación se le impone la obligación social de reducir en lo posible el coste del que le invita» (Haverkate, 1994: 108-9)

-Un acto amenazante para la imagen negativa del que realiza el acto. Ofrecer signilica desprenderse de algún tipo de bien, y en este sentido, representa una lesión del propio territorio.

2) Pcro, junto a esto, el ofrecimiento puede también considerarse como un acto anti-amenazante o un acto valorizador - «Face-Flattering Act ${ }^{3}$-, es decir, sus efectos son csencialmente positivos:

Un acto valorizador para la imagen positiva del otro, en tanto en cuanto, el otro aparece como digno y merecedor de que se le ofrezca algo. Si tenemos en cuenta que en la interacción se presupone que existe un deseo de preservar las imágenes públicas de uno y otro, el ofrecimiento demuestra las buenas intenciones del locutor de satisfacer la imagen positiva de su interlocutor.

-Un acto valorizador para la imagen positiva de uno mismo, en tanto en cuanto, ofrecer, al resultar algo positivo para el otro, pone de relieve mi cara positiva, mi generosidad...

Así pues, vemos que ofrecer es un acto ambivalente: puede resultar tan agradable como molesto, tanto para el locutor como para el interlocutor.

\section{Realizaciones lingüísticas del ofrecimiento y procedimientos de cortesía}

Pasamos a continuación a examinar las principales realizaciones lingüísticas del ofrecimiento en francés, el compromiso de las distintas imágenes en ellas, y los procedimientos de cortesía que intervienen en ellas.

Para la realización de este estudio, nos hemos basado principalmente en el corpus de Un niveau-seuil, que como es sabido, presenta para una multiplicidad de

\footnotetext{
${ }^{3}$ Término tomado de Kerbrat-Orecchioni, 1996, 54: «ll est indispensable d'introduire dans le modèle théorique un terme supplémentarie pour désigner ces actes qui sont en quelque sorte le pendant positif des FTA's: ces «anti-FTA 's» nous les appelerons des FFAs (Face Flattering Acts)».
} 
actos de habla del lrancés, las realizaciones lingüísticas más corrientes; también nos hemos basado en Chamberlain y alt. (1985)

Nuestra elección se circunscribe a formas «rutinizadas», en el sentido de Coulmas (1981) y Aijmer( 1996), es decir, estructuras gramaticales de forma estable en todos los contextos en los que ocurren, ligadas a una función especial o a una situación de comunicación.

La clasificación de los datos la realizamos de acuerdo con una distribución clásica de los actos de habla según el tipo de estructura:
A. Declarativa
B. Imperativa
C. Interrogativa.

\section{A. Declarativas.}
A.1. (1) Allcz, viens, je t’emmène au cinéma.
(2) Je vous accompagne
(3) Je vous apporte une chaise

En cstos cnunciados el ofrecimiento se plantea directamente, sin ninguna intermediación. Se trata de formulaciones directas, claras, no ambigüas, que, como tales, pucden resultar más agresivas para el territorio del interlocutor. Sin embargo, su uso suele hacerse en aquellas situaciones en las que el peligro para la imagen del interlocutor es mínimo, ya que su planteamiento comunica que:

- cl costc para el locutor es de poca importancia

-cs obvio cl interés que tiene para el interlocutor.

En estas formulaciones el locutor predica un acto futuro de sí mismo. Su carácter asertivo pucde considcrarse cortés, en el sentido de que le inducen al interlocutor a aceptar el ofrccimiento; se sobreentiende que ese ofrecimiento resulta beneficioso para él, ya que, en principio, no se le induciría a aceptar algo que no fuera beneficioso. También son corteses (cortesía positiva) cstos cnunciados en el sentido de que acortan la distancia en la relación entre los interlocutores.

Con todo, cstos ofrccimientos crean una presión en el destinatario: aunque se plantean con la previsión de aceptación del interlocutor, de hecho le presionan a aceptar y le dejan menor libertad de respuesta. Un rechazo, por ser una respuesta claramente no preferida, demandaría mayor justificación que otros casos, y supondría un riesgo para la imagen del locutor. Mediante cstas formulaciones, el locutor pone pues en riesgo su propia imagen. Con objeto de atenuar csà presión sobre la imagen negativa del interlocutor, es frecuente añadir:

(4) Je vous accompagne, si cela vous fait plaisir

si cela peut vous arranger

si cela peut vous rendre service etc 
Al tratarse de actos focalizados en el locutor, éste pone totalmente a su cargo el ofrecimiento, acentúa su responsabilidad en el ofrecimiento y deja menos espacio en la interacción para el interlocutor. Incurre en una fuerte implicación y deuda frente a sí mismo, y por lo tanto, en más riesgo para él.

Por otra parte, estas formulaciones acentúan la valoración de la imagen positiva del otro; al ser el ofrecimiento directo, es más firme, y por tanto más evidente

(5) Je passerai te voir la semaine prochaine

Sea o no sea sincero el ofrecimiento, en él se muestra el deseo del locutor de agradar a su interlocutor, y por tanto, de mantener su cara positiva.

A.2. a) (6) Je peux vous indiquer le chemin

b) (7) Je veux bien vous accompagner

En los enunciados del tipo a) se aserta la condición de que el locutor es capaz de cumplir la acción que se ofrece. En los enunciados del tipo b) se aserta la condición de que el locutor está dispuesto a cumplir la acción que se ofrece. Se trata de realizaciones indirectas del acto de habla.

Estas realizaciones indirectas atenúan el valor de FTA del ofrecimiento de la siguiente manera: restando la carga de deuda al interlocutor, y acentuando el escaso coste que supone para el locutor. Ello facilita al interlocutor aceptar la oferta. Si tencmos en cuenta la escala de coste-beneficio de Leech(1983), las formas que suponen mayor coste para el locutor resultan más corteses.

Sin cmbargo, al estar focalizadas en el «yo», dichas formas suponen un alto riesgo para la imagen negativa del locutor, ya que éste se expone más en la interacción.

Pueden venir mitigadas por procedimientos de cortesía que acompañan a la formulación, y cuyo efecto es mitigar la invasión en el territorio del otro, como por cjemplo:

(8) Si cela peut vous être utile/agréable, je peux vous accompagner.

Cuando se enuncian en condicional:

(9) Je pourrais te prêter de l'argent

(10) Je pourrais te laisser mon vélo

se trata de ofertas suavizadas, menos en firme que las anteriores, debido a la desactualización que produce el condicional. Como consecuencia, ejercen menos presión sobre el destinatario. 
Por otra parte, el carácter asertivo de las formulaciones del tipo; «Je peux...»o «Je veux...» resalta la valorización de la cara positiva del locutor, y por ende, la cara positiva del interlocutor, que aparece merecedor del ofrecimiento.
A.3. Pre-ofrecimientos
(11) J'ai une bouteille de ton vin préféré chez moi.
(12) Je viens de faire du café. Tu en veux?
(13) J'ai tous ses romans chez moi, je ne sais pas si ça t'intéresse ou pas.

Estas secuencias anuncian y preparan el ofrecimiento que viene a continuación. Ese ofrecimiento puede ser explícito, como en el caso del ejemplo (12), o implícito, en cuyo caso la propia secuencia previa constituye por ella misma el ofrecimiento.

Un medio de suavizar un acto delicado es anunciarlo por medio de una «secuencia previa». Estas secuencias poseen una gran importancia en la amortiguación de los FTA en la comunicación, y se utilizan en diversos actos de habla. Constituyen un procedimiento de cortesía negativa.

Estas formas representan los procedimientos más indirectos del acto de habla. Son así las que menor amenaza suponen para el territorio del otro, al que incluso le puede ocurrir no tener clara su función, no estar seguro de su interpretación:

\section{(14) -J'ai un poulet à la maison}

- Et alors?

También puede aprovecharse del disfraz del acto de donación bajo una forma afirmativa, fingir que no ha entendido el acto rutinizado socialmente y que lo interpreta literalmente:

\section{(15) -J'ai un poulet à la maison}

$-\mathrm{Ah}$, hon? Vous avez un poulet à la maison?

Aunque esta misma interacción sería válida si el interlocutor quiere asegurarse de la función de lo comunicado por el locutor, y busca que éste sea más explícito.

Muy frecuentemente, se recurre a esta estrategia para evitar comprometerse en cl acto de habla, o para evitar comprometerle al otro.

Así después de una liesta, dos personas, A y B se despiden y una le dice a la otra:

(16) Vous ĉtes venu en voiture? 
enunciado preliminar por el que $\mathrm{A}$ anuncia que va a realizarle un ofrecimiento: llevarle a casa. Posee una serie de ventajas en la comunicación:

-Si B le contesta «oui», A puede evitar realizar a continuación el ofrecimiento, y por tanto ahorrarse el acto de habla comprometedor.

Puede ocurrir que B no desee que A le lleve a casa. Entonces puede contestar un «oui» no sincero. Significaría que B no quiere que A siga adelante con el ofrecimiento y así evitar el rechazo, que siempre es molesto en la interacción. La secuencia previa le evita a nuestro interlocutor tener que rechazar, y por tanto emilir un FTA.

-B cntendería normalmente el carácter de secuencia previa a un ofrecimiento, ya que se trata de estrategias rutinizadas socialmente. Si contesta «non» da vía libre á A para que realice el ofrecimiento. De este modo, plantear el ofrecimiento tiene altas posibilidades entonces de verse seguido por la aceptación. Es decir, que las secucncias previas facilitan el preservar las imágenes de los interactuantes.

Puede pensarse que las secuencias previas no son fórmulas convencionalizadas.Sin embargo, como afirma Tsui (1994), en relación con los «pre-requests», pero igualmente válido para nuestro caso:

«it is a face-saving strategy that is so commonly employed that conventionalization occurs» (1994:111).

\section{B. Imperativas.}

(17) Prends unc autre bière.

(18) Servez-vous

(19) Asseycz-vous, s'il vous plaît

(20) Tene\%, j’ai pensé que ça vous ferait plaisir (en offrant des fleurs)

Estos cnunciados representan realizaciones directas del ofrecimiento. En ellos, su carácter dirccto pone de relieve el interés del locutor en satisfacer la imagen positiva del interlocutor, acentúan el acercamiento entre ambos, y por tanto constituyen un procedimiento de cortesía positiva. Corolariamente ponen de relieve la imagen positiva del locutor, que es quien realiza el ofrecimiento.

Con respecto al impacto sobre la imagen negativa del otro, resultan amcnazantes para esa imagen, pero como en la interacción armoniosa se busca generalmente preservar la imagen ajena, estas formas tienden a utilizarse en situaciones que suponen poco riesgo para el interlocutor, cuando conocemos el terreno ajeno y por tanto podemos medir con más seguridad ese riesgo.

Pueden venir acompañadas de mitigadores del acto de habla del tipo:

(21) Asseycz-vous, Madame, si vous voulez. 
El imperativo suele asociarse a actos de tipo directivo y resultar por ello no cortés. Es el caso de la petición, por ejemplo, en el que el uso del imperativo se considera impositivo, y por tanto, no cortés. Sin embargo, en el caso del ofrecimiento, el imperativo puede considerarse, al contrario, una marca de cortesía, ya que se exhorta a que el interlocutor acepte el ofrecimiento por tratarse de algo beneficioso para él, pues al formularse de manera imperativa se resalta el hecho de que cl acto constituye un bien para el destinatario. Así, la imposición se siente tanto menos cuanto que la acción beneficia al interlocutor.

La cortesía aquí también viene dada por otro factor: al uso del imperativo subyace la asunción de un terreno común, compartivo entre los interlocutores, se asume que existe poca distancia entre ellos, poca diferencia de poder. Es lo que Scollon y Scollon(1995) llaman «cortesía de solidaridad».

\section{Interrogativas.}

C.1. Je vous accompagne?

(22) Encore un peu de gâteau, Madame?

(23) Je vous coupe cette viande en morceaux?

(24) Vous préférez que je revienne demain?

Se trata de formulaciones indirectas del acto de habla, en las que se pretende atenuar cl carácter de FTA del ofrecimiento por medio de una pregunta, menos cocrciliva que una aserción. La pregunta deja libertad de respuesta al interlocutor (aceptación/rechazo), y mitiga la amenaza al territorio ajeno. Siempre es molesto rcchazar, pero las preguntas permiten rechazar la oferta, y aunque el rechazo no es una respuesta preferida en un ofrecimiento, aquí supone menor impacto para la imagen negativa del locutor que las formas directas.

Decimos que el rechazo es una respuesta no preferida, pero hay que tener en cuenta que en ocasiones, lo cortés es rechazar"

«It is polite to offer someone something, but it is also often more polite to decline an offer than to accept it»(Leech, 1983: 169)

El rechazo suele acompañarse de una justificación. Por ejemplo, un rechazo no cortés al ofrecimiento:

\footnotetext{
${ }^{4}$ En algunas culturas, se hace el ofrecimiento, se rechaza, se vuelve a hacer, se rechaza, se hace de nuevo, y al final, se acepta o se rechaza. Brown y Levinson (1987:233) dan el siguiente ejemplo:

A I: Would you like a drink?

B 1: Oh no, it's all right.

A2: No, I insist

B2: OK, l'd love a double whisky.

Esto se explica por el hecho de que aceptar un ofrecimiento se considera un FTA.
} 
(25) Encore un peu de gâteau, Madame?

seria

(26) Non

Un rechazo cortés sería:

(27) Non, merci, je suis un régime.

Con respecto a la valorización de las imágenes públicas positivas de los comunicantes, si bien el ofrecimiento supone esa valorización por definición, esa valorización tendría un grado menor que otras formas como $\mathrm{A}$.

C.2. (28) Souhaitez-vous que je vous accompagne?

(29) Voulez-vous que j"cn parle au directeur?

(30) Aimeriez-vous que je vous accompagne?

(31) Tu veux que je t’aide à faire le travail?

En estos ofrecimientos se interroga sobre una de las condiciones del acto de habla: si el interlocutor desea que el locutor cumpla el acto. Se trata de formas indirectas del ofrecimiento, que pretenden minimizar la eventual molestia que puede suponer el acto para el interlocutor, y que por lo tanto constituyen un procedimiento de cortesía negativa. Se mitiga así el carácter amenazante del acto de habla, permitiendo la opcionalidad en la respuesta por medio de la pregunta y plantéándole al interlocutor si desea que el locutor realice el acto ofrecido.

Sc trata de ejemplos enfocados hacia el oyente -aunque exista una referencia al hablante - por medio de los cuales el locutor aparece menos responsable de realizar la oferta. Esto último implica que la imagen negativa del locutor se pone menos en juego en la interacción.

Los verbos de estos enunciados en ocasiones se usan en condicional:

(32) Voudriez-vous une livraison à domicile?

El condicional sería aquí un grado más de cortesía negativa, y sirve para poner más a distancia la realización del acto; funciona como un atenuante del acto.

El que el locutor ponga más a distancia el ofrecimiento que realiza revierte en un menor efecto de valorización del acto para las imagenes positivas tanto de uno como de otro protagonista de la interlocución. 


\section{C.3. Pouvoir ?}

(33) Est-ce que je peux vous offrir un café?

(34) Est-ce que je peux vous aider?

Se irata de un procedimiento de cortesía negativa, que atenúa el efecto de FTA del acto. Se presenta la olerta bajo la forma de pedir permiso para realizarla: el resultado es que el locutor se comporta como si la acción le fuera a ser beneficiosa a él. Es curioso cómo para cvitar la injerencia en el territorio personal del otro, se recurra a un desplazamiento por el que un ofrecimiento se plantea como una pelición, en la que el locutor se coloca en un plano «inferior» al interlocutor.

Estas formulaciones representan una amenaza mínima para el otro, $y$, sin cmbargo, al plantcar la acción bajo la forma de una pregunta de permiso y como para beneficio del loculor, resulta difícil rechazarlas. Estando enfocadas hacia el locutor, suponen un alto riesgo para su imagen negativa, ya que éste se pone a merced del interlocutor.

Ofrecimientos indirectos como éstos resultan anti-amenazantes para uno y otro inierlocutor, en sus imágenes positivas.

Mostramos a continuación un cuadro que recoge la activación de las distintas imágenes del locutor e interlocutor, protagonistas de la interacción, según la formulación lingüística:

\begin{tabular}{|c|c|c|c|c|}
\hline & \multicolumn{2}{|l|}{ LOCUTOR } & \multicolumn{2}{|l|}{ INTERLOCUTOR } \\
\hline & $\begin{array}{l}\text { Riesgo para su } \\
\text { imagen negativa } \\
(+/-)\end{array}$ & $\begin{array}{l}\text { Valoración de su } \\
\text { imagen positiva } \\
(+/-)\end{array}$ & $\begin{array}{l}\text { Riesgo para su } \\
\text { imagen negativa } \\
(+/-)\end{array}$ & $\begin{array}{l}\text { Valorización de } \\
\text { su imagen } \\
\text { positiva }(+t-)\end{array}$ \\
\hline $\begin{array}{l}\text { A.DECLARATIVAS } \\
\text { A.1. Je vous } \\
\text { accompagne }\end{array}$ & + & + & + & + \\
\hline $\begin{array}{l}\text { A.2. Je peux/veux } \\
\text { vous accompagner }\end{array}$ & + & + & - & + \\
\hline $\begin{array}{l}\text { A.3. Je viens de laire } \\
\text { du calé (pre- } \\
\text { ofrecimiento) }\end{array}$ & - & - & - & - \\
\hline $\begin{array}{l}\text { B. IMPERATIVAS } \\
\text { Prends the atutre } \\
\text { bière }\end{array}$ & + & + & + & + \\
\hline $\begin{array}{l}\text { C. } \\
\text { INTERROGATIVAS } \\
\text { C. } 1 . \text { Je vous coupe } \\
\text { celte viande en } \\
\text { morceaux? }\end{array}$ & - & - & - & - \\
\hline $\begin{array}{l}\text { C.2.Voulez-vous que } \\
\text { je vous accompagne? }\end{array}$ & - & - & - & - \\
\hline
\end{tabular}




\begin{tabular}{|l|l|l|l|l|}
\hline $\begin{array}{l}\text { C.3. Est-ce que je } \\
\text { peux vous offirir un } \\
\text { café? }\end{array}$ & & - & - & - \\
\hline
\end{tabular}

\section{Conclusiones}

En este estudio hemos analizado la puesta en escena de las cuatro imágenes (locutor-positiva y negativa-, interlocutor-positiva y negativa-) presentes en las distintas realizaciones linguísticas del ofrecimiento, junto a los procedimientos de cortesía involucrados en ellas. Si hemos definido el ofrecimiento como un acto al mismo tiempo amenazador de la imagen del locutor y del interlocutor, y valorizador de la imagen del locutor y del interlocutor, las distintas formulaciones linguiísticas no ponen en juego esas características de la misma manera.

Se concibe generalmente que ofrecer resulta un acto beneficioso para el otro y por tanto cortés; la cortesía inherente a los actos corteses se considera cortesía positiva (Haverkate, 1994). Las formas directas del ofrecimiento, como A.1. y B, son los exponentes de cortesía positiva: buscan un acercamiento, una proximidad entre los interlocutores, muestran solidaridad. Sin embargo, la mayoría de las formas que existen en francés para ofrecer algo a alguien se construyen como formas indirectas del acto de habla, y se cargan de cortesía negativa. Esto supone que ofrecer en francés significa sobre todo amenazar el territorio ajeno, y la práctica totalidad de formas lingüísticas rutinizadas se encaminan a mitigar ese efecto de amenaza, de invasión del territorio ajeno.

La mayoría de las formas lingüísticas del ofrecimiento, pues, tienden a minimizar ese riesgo al territorio del otro, pero esto tiene también sus efectos sobre la valorización ajena, ya que, mitigar ese riesgo conlleva rebajar la imagen positiva ajena. Dicho de otra manera, lo que protege a la imagen ajena merma su exaltación. Por otro lado, minimizar el riesgo de invasión del terreno ajeno redunda en minimizar el riesgo propio, es decir, al proteger la imagen ajena, se protege la propia; esto sucede así excepto en las formas orientadas hacia el locutor, ya que en estos casos, el locutor se expone más, y por tanto, el riesgo para él es mayor. Además, protegiendo la propia imagen, ésta destaca menos.

Las formas directas amenazan más el territorio ajeno, pero al mismo tiempo muestran mayor interés en el otro. Al amenazar más el territorio ajeno, ponen más en riesgo el propio, pero también resaltan la propia generosidad.

Recapitulando, ofrecer en francés significa principalmente prevenir la intrusión que ello puede suponer para el interlocutor, lo cual resta relieve el aspecto positivo del ofrecimiento. Ofrecer no es pues esencialmente un acto cortés, favorecedor de cortesía positiva, sino un acto de riesgo en la interacción personal, portador de cortesía negativa. 


\section{Referencias bibliográficas:}

Aijmer, K. (1996): Conversational routines in English. Convention and creativity, Londres \& Nueva York: Longman.

Ach, K. And Harnish, R. M. (1979): Linguistic communication and speech acts, Cambridge, Mass: The MIT Press.

Bérard, E. \& Lavenne, C. (1989): Grammaire utile du français. París: Hatier.

Brown, P. \& Lcvinson, S. (1987): Politeness. Some universals in language usage,

Cambridge: Cambridge University Press.

Chamberlain, A. \& Stecle, R. (1985): Guide pratique de la communication. París:

Didicr

Coste, D. cl alt. (1986): Un niveau-seuil. París: Hatier.

Coulmas, F. (ed.) (1981): Conversational routine, La Haya: Mouton

Escandell Vidal, M.V. (1996): Introducción a la pragnática. Barcelona: Ariel Linguiística.

Golfman, E. (1973): La mise en scène de la vie quotidienne (2 vol). París: Minuit. Goffiman, E. (1974): Les rites d'interaction. París: Minuit.

Hancher, M. (1979): «The classification of cooperative illocutionary acts», Language in Society $8(1$, págs. 1-14

Haverkate, H. (1994): La cortesía verbal. Estudio pragmalingiuístico. Madrid: Gredos.

Kerbrat-Orcechioni, C. (1992): Les interactions verbales (tome II). París: Armand Colin.

Kerbrat-Orcechioni, C. (1996): La conversation. París: Seuil «Mémo».

Lacroix, M. (1990): De la politesse. Essai sur la littérature du savoir-vivre. París: Commentaire/Julliard.

Lccch, G. (1983): Principles of pragmatics. Londres: Longman.

Levinson, S. (1983): Pragmatics. Cambridge: Cambridge University Press.

Roulet, E. (1977): «Étude des réalisations directes et indirectes de l'acte d'offre en français parlé», Studi italiani di linguistica teorica ed applicata, VI, págs. 525539

Scollon, R. \& Scollon, S.W.(1995): Intercultural communication. OxfordCambridge: Blackwcll.

Tsui, A. B. M. (1994): English conversation, Oxford: Oxford University Press.

Watts, R. ct alt. (cds) (1992): Politeness in language. Studies in its history, theory and practice, Bcrlín. Mouton de Gruyter. 